\title{
Fragmentation vs. functionalization: chemical aging and organic aerosol formation
}

\author{
H. J. Chacon-Madrid and N. M. Donahue \\ Center for Atmospheric Particle Studies, Carnegie Mellon University, Pittsburgh, Pennsylvania 15213, USA \\ Received: 19 April 2011 - Published in Atmos. Chem. Phys. Discuss.: 5 May 2011 \\ Revised: 16 September 2011 - Accepted: 23 September 2011 - Published: 25 October 2011
}

\begin{abstract}
The transformation process that a carbon backbone undergoes in the atmosphere is complex and dynamic. Understanding all these changes for all the species in detail is impractical; however, choosing different molecules that resemble progressively higher stages of oxidation or aging and studying them can give us an insight into general characteristics and mechanisms. Here we determine secondary organic aerosol (SOA) mass yields of two sequences of molecules reacting with the $\mathrm{OH}$ radical at high $\mathrm{NO}_{\mathrm{x}}$. Each sequence consists of species with similar vapor pressures, but a succession of oxidation states. The first sequence consists of $n$-pentadecane, $n$-tridecanal, 2-, 7-tridecanone, and pinonaldehyde. The second sequence consists of $n$-nonadecane, $n$-heptadecanal and cis-pinonic acid. Oxidized molecules tend to have lower relative SOA mass yields; however, oxidation state alone was not enough to predict how efficiently a molecule forms SOA. Certain functionalities are able to fragment more easily than others, and even the position of these functionalities on a molecule can have an effect. $n$ Alkanes tend to have the highest yields, and $n$-aldehydes the lowest. $n$-Ketones have slightly higher yields when the ketone moiety is located on the side of the molecule and not in the center. In general, oxidation products remain efficient SOA sources, though fragmentation makes them less effective than comparable alkanes.
\end{abstract}

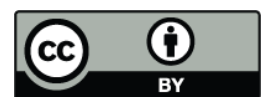

Correspondence to: N. M. Donahue (nmd@andrew.cmu.edu)

\section{Introduction}

Organic oxidation mechanisms in the atmosphere are very complex and dynamic. After a molecule is emitted, it is transformed via reaction with the $\mathrm{OH}$ radical, ozone, $\mathrm{NO}_{3}$ radical, and photolysis, etc. forming a rich array of products. The number of product molecules increases with increasing carbon number in the precursor-molecule as well as with the extent of oxidation (Goldstein and Galbally, 2007; Kroll and Seinfeld, 2008). Consequently, mechanisms associated with organic aerosol, which generally involve higher than average carbon numbers and significant oxidation (Hallquist et al., 2009), are especially complex. Smog-chamber experiments have constrained parts of many reaction mechanisms; for example the first-generation products of $n$-alkanes with the $\mathrm{OH}$ radical have been identified in detail (Atkinson et al., 2008; Lim and Ziemann, 2005; Atkinson and Arey, 2003), but in most cases only the first hours of reaction are well understood. A typical aerosol particle resides in the atmosphere between one to two weeks (Balkanski et al., 1993; Kanakidou et al., 2005) before removal. This time scale is significantly longer than most smog-chamber experiments. There is thus a critical need to understand later-generation chemistry of the oxygenated compounds likely to be involved in the full life cycle of organics, and especially organic aerosol, in the atmosphere.

Studying the transformation of chemical species for weeks in smog-chamber experiments under ambient conditions is not possible; hence some studies have increased the oxidant concentration (e.g. $\mathrm{OH}$ radical) to simulate multiple days of oxidation (Kroll et al., 2009; Smith et al., 2009; George et al., 2007). These studies, done in flow tubes, have started to yield insight into chemical aging. However, there is limited research on this topic, and the very high oxidant exposures may skew the oxidation mechanisms. Understanding the details of how molecules age in the atmosphere is crucial

Published by Copernicus Publications on behalf of the European Geosciences Union. 
for models that predict secondary organic aerosol (SOA) formation (Kanakidou et al., 2005) as well as subsequent transformation (Rudich et al., 2007). One way to elucidate this multiple-generation chemistry is to follow it one generation at a time. The idea is to carefully select compounds that are either themselves important intermediates, or that represent important classes of compounds with similar properties. Here we take this approach.

Efforts are underway to try to classify atmospherically relevant organic material in terms of properties important to the condensed phase. The most important property is volatility - it determines whether a compound is in the condensed phase at all (Donahue et al., 2006). Oxygenation has been proposed as a second important property because it progressively increases during oxidation chemistry and also appears to correlate well with water solubility, another key property (Jimenez et al., 2009). We can describe volatility in terms of the saturation concentration, $C^{\circ}$ (Donahue et al., 2006; Donahue et al., 2011a, b), which is operationally defined as the organic aerosol concentration $\left(C_{\mathrm{OA}}\right)$ at which half of a given compound will be found in the condensed phase (Donahue et al., 2006). For oxygenation we employ the oxygen-to-carbon ratio O:C (Jimenez et al., 2009; Donahue et al., 2011a).

It is useful to break reaction mechanisms into a succession of steps connecting one stable molecule to another. We can classify these steps as functionalization, fragmentation and accretion (Kroll and Seinfeld, 2008; Rudich et al., 2007) according to the effect on the product carbon number. These three processes are illustrated in Fig. 1. Functionalization involves the addition of oxygenated functional groups (thus an increase in $\mathrm{O}: \mathrm{C}$ ) to a molecule with no change in carbon number, decreasing its vapor pressure in most cases and making it more likely to partition into the aerosol phase. Fragmentation refers to carbon-carbon bond cleavage resulting in at least two separate organic products (i.e. a reduction in carbon number). In some cases, this path creates higher vapor pressure species, and in others, the vapor pressure decreases because the products are typically also functionalized. A good example is the ozonolysis reaction of monoterpenes. While the double bond is broken, at least two oxygens are added, often significantly decreasing the vapor pressure of the products compared to the parent-molecule. Finally, accretion, also named oligomerization, refers to association reactions (typically in the condensed phase) resulting in an increase in carbon number (with no change in O:C) and a dramatic reduction in vapor pressure (Kalberer et al., 2004, 2006). While not all accretion reactions lead to lower vapor pressure species (for example esterification), often the increase in carbon number outweighs any reduction in polarity.

The relative effects of these three pathways on organicaerosol levels and properties remain uncertain. Thermodynamics demands that complete fragmentation (formation of $\mathrm{CO}_{2}$ ) would be the outcome if oxidation continued far enough (Kroll et al., 2011), but most carbon emissions re-

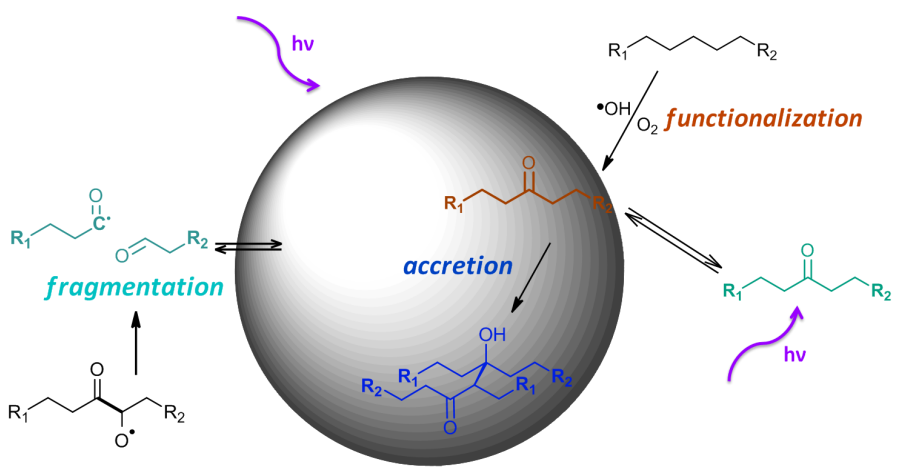

Fig. 1. Major mechanisms in gas and aerosol-phase oxidation. The three major chemical mechanisms that a carbon backbone undergoes in the atmosphere are represented along with their interaction with aerosols. They are described and revised in Kroll and Seinfeld (2008) and Rudich et al. (2007). Both, functionalization and accretion tend to decrease the vapor pressure of species by either adding polarity to the molecule or by accreting with other molecules. Fragmentation cleaves carbon-carbon bonds of molecules, generally increasing the vapor pressure of products; however, a good exception is the ozonolysis of monoterpenes, where both fragmentation and functionalization happen simultaneously, adding polarity and decreasing the overall vapor pressure of the products. The competition of these three mechanisms define the fate of molecules in the atmosphere, but it is not clear how this competition plays out while molecules and particles age.

turn to the surface before complete oxidation (Goldstein and Galbally, 2007). Ambient organic aerosol is highly oxidized (Ng et al., 2010) (with average oxygen to carbon ratios for aerosols varying from 0.5 to $0.9, \mathrm{Ng}$ et al., 2010; Aiken et al., 2008), with significant carboxylic acid functionality (Rudich et al., 2007), but this does not directly indicate how much of a role fragmentation or accretion plays.

Another issue is the phase in which the chemistry occurs. The primary focus here is on gas-phase chemistry, where both functionalization and fragmentation reactions can occur readily. Heterogeneous uptake of oxidants (i.e. $\mathrm{OH}$ ) can have similar effects (Kroll et al., 2009). Accretion reactions occur in the condensed phase, either in a primarily organic phase or in the aqueous phase. For the experiments reported here the relative humidity was kept low $(\mathrm{RH}<10 \%)$, and so any condensed phase chemistry occurred in the organic phase. It is also possible that reactive uptake of organic peroxyl radicals $\left(\mathrm{RO}_{2}\right)$ could influence the organic oxidation mechanism and also SOA formation. However, all experiments described here were performed under high- $\mathrm{NO}_{\mathrm{x}}$ conditions. The timescale for collisions with aerosols (the condensational sink) was significantly longer than the fast $\mathrm{RO}_{2}+\mathrm{NO}$ reaction (Atkinson et al., 1987; Arey et al., 2001), so peroxyl uptake was not significant for the experiments presented here. 
While organic aerosol ages in the atmosphere, its oxygenation (indicated by the oxygen to carbon ratio, O:C) tends to increase, changing its properties with time ( $\mathrm{Ng}$ et al., 2010). We would therefore like to examine the fragmentation susceptibility and SOA formation of individual molecules versus oxygenation. In order to do this, we selected two different sequences of molecules, each sequence consisting of atmospherically relevant vapor pressures (Fig. 2). Specifically, we work with molecules that have saturation concentrations (vapor pressures in mass concentration units) of $\sim 10^{5}$ and $\sim 10^{3} \mu \mathrm{g} \mathrm{m}^{-3}$. For each sequence, we concentrate on molecules that have a different $\mathrm{O}: \mathrm{C}$, and that are atmospherically relevant. The highest O:C we have worked with so far is $\sim 0.3$ : atmospherically relevant molecules with higher $\mathrm{O}: \mathrm{C}$ are more difficult to synthesize, separate or obtain commercially. In this manner we are systematically constructing a sequence of oxidation steps, using model compounds to represent both locations in the 2-D space as well as successive generations of oxidation. Since vapor pressure data are not available for all of the species we worked with, we used the SIMPOL model from Pankow and Asher (2008) and fits from Donahue et al. (2011a) to estimate them. The major characteristic encountered is that a molecule with $n$ carbons has a similar vapor pressure to a molecule with $n$ 2 carbons and 1 oxygen (with carbonyl functionality). This characteristic is used only as a guide.

Each sequence contains species with similar vapor pressures because comparison of their SOA mass yields reflects the competition between fragmentation, functionalization and possibly accretion if important. If two different chemical species with identical vapor pressures had very similar chemical oxidation paths (e.g. competition of functionalization, fragmentation and accretion) their SOA mass yields are expected to be similar as well. That is because with every generation of products formed, their overall vapor pressures increase or decrease by a similar amount. If the SOA mass yields are very different, then the different classes of reaction pathways (fragmentation, functionalization and accretion) contribute differently to the oxidation mechanism. This approach is similar to that employed by Ziemann and coworkers to explore the effects of branching, unsaturation and cyclization on hydrocarbon SOA formation (Lim and Ziemann, 2009a, b), but our focus is on the effects of oxygenated functionality as a model for later-generation chemistry.

The $10^{5} \mu \mathrm{g} \mathrm{m}^{-3}$ sequence is $n$-pentadecane, $n$-tridecanal, pinonaldehyde, 2-tridecanone, and 7-tridecanone. nPentadecane is the "anchor" species in the sequence, defining the nominal SOA mass yields we expect from a $\sim 10^{5} \mu \mathrm{g} \mathrm{m}$ species. Both $n$-pentadecane and $n$-tridecanal (Schauer et al., 1999a, b) are good models of important anthropogenic emissions with respect to chemical and structural characteristics (e.g. vapor pressure, oxidation state, etc.). Pinonaldehyde is a major product of the oxidation of $\alpha$-pinene (Schradera et al., 2005; Glasius et al., 1997); multiple studies indicate that the molar yield formation of pinonaldehyde from both $\alpha$-pinene ozonolysis and $\mathrm{OH}$ radical reaction can approach 50\% (Hatakeyama et al., 1989, 1991), making it a good model-molecule of the first-generation products from the oxidation of monoterpenes. Finally, 2-tridecanone and 7-tridecanone allow us to explore the relationship between the position of carbonyl functionality in the molecule and its ability to fragment.

The $10^{3}$ sequence is $n$-nonadecane, $n$-heptadecanal and cis-pinonic acid. Both $n$-nonadecane and $n$-heptadecanal are chosen as homologous to $n$-pentadecane and $n$-tridecanal. cis-Pinonic acid is similar to pinonaldehyde and it is also a first-generation product of $\alpha$-pinene oxidation (Hatakeyama et al., 1991).

Our hypothesis is that there is a relationship between the oxidation state of a molecule and its ability to form SOA. More oxidized molecules can fragment more easily, as shown by Kroll et al. (2009), reducing their ability to form organic aerosol when reacting with the $\mathrm{OH}$ radical. Chacon-Madrid et al. (2010) showed that $n$-aldehydes fragment significantly more than $n$-alkanes with similar vapor pressures, thus forming less SOA. When examining the gas-phase chemistry of different volatile organic compounds (VOCs) with the $\mathrm{OH}$ radical in the presence of $\mathrm{NO}_{\mathrm{x}}$ (Atkinson and Arey, 2003; Atkinson, 2000, 2007), it is clear the alkoxy radical is the leading intermediate that fragments molecules, especially when other functionalities are already present (Atkinson, 2007; Kwok et al., 1996).

Our objectives are to (a) understand the relationship between the oxidation state of a molecule and its ability to form organic aerosol, (b) realize how important fragmentation vs. functionalization paths are while a molecule ages in the atmosphere and (c) report SOA mass yields of atmospherically relevant species for which there is limited or no information in the literature. Our model-system does not present highly oxidized precursors as seen in Fig. 2, limiting our conclusions to precursors similar to those found in the early steps of $\mathrm{OH}$ radical oxidation sequences. This limitation has to do with the difficulty of synthesizing, separating or obtaining commercially material that resembles low volatility-oxidized organic aerosol (LV-OOA) (Ng et al., 2010).

\section{Experimental}

We conducted experiments in the Carnegie Mellon University smog chamber. Many details of our experimental procedures are described elsewhere (Hildebrandt et al., 2009). The FEP Teflon (Welch Fluorocarbon) chamber has a maximum volume capacity of $12 \mathrm{~m}^{-3}$. The bag is suspended inside a temperature-controlled room, which was held at $295 \mathrm{~K}$ for these experiments. All the experiments were conducted under high- $\mathrm{NO}_{\mathrm{x}}$ conditions (maximum of $\left.4 \mathrm{ppbC} \mathrm{ppb}^{-1}-\mathrm{NO}_{\mathrm{x}}\right)$. Table A in the Supplement lists the specific concentrations and important concentration ratios for all the experiments. Particle number-size distributions 


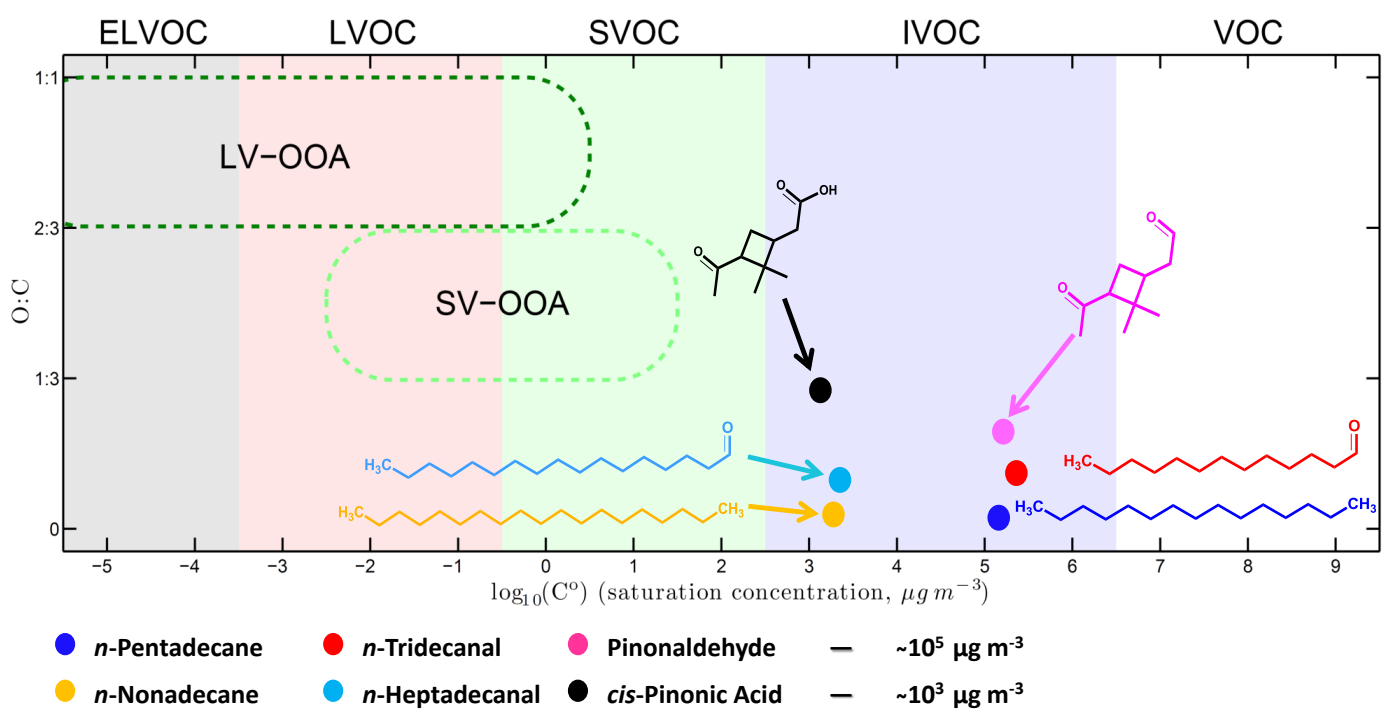

Fig. 2. Two sequences of molecules with progressively increasing oxidation state but similar vapor pressures $\left(\sim 10^{5}\right.$ and $\left.\sim 10^{3} \mu \mathrm{g} \mathrm{m}^{-3}\right)$, shown in a two-dimensional volatility-oxidation state space. The $10^{5} \mu \mathrm{g} \mathrm{m}^{-3}$ sequence is: $n$-pentadecane, $n$-tridecanal, pinonaldehyde, and 2- and 7-tridecanone (co-located with $n$-tridecanal). The $10^{3} \mu \mathrm{g} \mathrm{m}^{-3}$ sequence is: $n$-nonadecane, $n$-heptadecanal and cis-pinonic acid. The species lie in the intermediate volatile organic carbon (IVOC) range occupied by many first-generation oxidation products associated with secondary organic aerosol (SOA) formation. Pinonaldehyde and cis-pinonic acid are first-generation products of $\alpha$-pinene oxidation. Ambient oxidized organic aerosol (OOA) lies in the ranges indicated, with SV-OOA being fresher, less oxidized and more volatile and LV-OOA being more aged and less volatile.

were monitored using a scanning mobility particle sizer operating in recirculating mode (SMPS, TSI classifier model 3080 , CPC model 3772 or $3010,15-700 \mathrm{~nm} D_{\mathrm{p}}$ ). The concentrations of the different organic species were monitored with a unit mass-resolution proton transfer reaction-mass spectrometer (PTR-MS, Ionicon $\mathrm{GmbH}$ ). For each experiment, HONO photolysis was used to create $\mathrm{OH}$ radicals. Additional nitric oxide (NO) was added to achieve the desired VOC: $\mathrm{NO}_{\mathrm{x}}$ ratio. Ammonium sulfate particles (Sigma Aldrich, $99.99 \%$ ) were used as inert seeds for condensation. These were formed from an aqueous solution with a nebulizer (TSI 3075), then dried and neutralized. We used seed concentrations of $\sim 10^{4}$ particles $\mathrm{cm}^{-3}$ or $\sim 10$ to $15 \mu \mathrm{g} \mathrm{m}^{-3}$. The organic species used were $n$-tridecanal (Alfa Aesar, $94 \%$ ), pinonaldehyde (synthesized in Carnegie Mellon Laboratory, $\sim 85 \%$ ), 2-tridecanone (MP Biomedicals), 7 tridecanone (MP Biomedicals), $n$-nonadecane (Ultra, 99\%), $n$-heptadecanal (synthesized in Carnegie Mellon Laboratory, $\sim 85 \%)$ and cis-pinonic acid (98\%, Aldrich). These molecules were all used without further purification. UV lights (General Electric 10526 black lights) with a $J_{\mathrm{NO}_{2}}=$ $0.06 \mathrm{~min}^{-1}$ were used to initiate photo-oxidation after all the components were mixed in the chamber.

\subsection{Injection of molecules into the chamber}

Molecules in the $10^{5} \mathrm{\mu g} \mathrm{m}^{-3}$ sequence were injected directly into the chamber via a septum. Molecules in the $10^{3} \mu \mathrm{g} \mathrm{m}-3$ sequence (Fig. 2) were injected into the chamber using a resistively heated vaporizer. This vaporizer has a resistive graphite tip where the material of interest is placed, which is suspended directly in the chamber. This vaporizer heats up to about $200^{\circ} \mathrm{C}$ in about two minutes. A steel tube is used to allow a flow of air to dissipate the material from the tip into the chamber. Some graphite is ejected from the tip while heated, but the concentrations are significantly lower than the organic precursors. Based on PTR-MS mass spectra of the injection products, there was no evidence of precursor decomposition during vaporization.

\subsection{SOA mass yield and wall loss calculations}

The SOA mass yield from a reaction is defined as the mass of organic aerosol formed divided by the mass of precursor consumed (Odum et al., 1996),

$Y=\frac{C_{\mathrm{OA}}}{\Delta C_{\text {precursor }}}$

where $C_{\mathrm{OA}}$ is the mass of organic aerosol created, and $\Delta C_{\text {precursor }}$ is the mass of the precursor organic species consumed to form the organic aerosol $\left(C_{\mathrm{OA}}\right)$ and other products. We determined SOA mass yields for the different organic species based on volume growth on the inorganic seeds, measured with the SMPS.

Total SOA production $\left(C_{\mathrm{OA}}\right)$ is determined by using the ratio of suspended organic aerosol $\left(C_{\mathrm{OA}}^{\mathrm{sus}}\right)$ to suspended 
ammonium sulfate $\left(C_{\text {sus }}^{\text {seed }}\right)$ and the initial concentration of ammonium sulfate $C_{\text {sus }}^{\text {seed }}(t=0)$, as described by Hildebrandt et al. (2009):

$C_{\mathrm{OA}}(t)=\frac{C_{\mathrm{OA}}^{\mathrm{sus}}(t)}{C_{\mathrm{sus}}^{\mathrm{seed}}(t)} C_{\mathrm{sus}}^{\mathrm{seed}}(t=0)$

$C_{\text {sus }}^{\text {seed }}(t)$ is obtained by fitting an exponential decay to the ammonium sulfate volume concentration (measured with the SMPS and verified with an Aerosol Mass Spectrometer) over the interval between seed injection (and mixing) in the chamber and the onset of photo-oxidation. Extrapolation of this signal after the photo-oxidation process starts defines the seed mass concentration as a function of time.

At time 0 (onset of photo-oxidation) and later, the difference between the total aerosol mass concentration in the chamber (measured with an SMPS) and the extrapolated ammonium-sulfate mass concentration is considered the $C_{\mathrm{OA}}^{\mathrm{sus}}(t)$. To obtain the total $C_{\mathrm{OA}}(t)$ from the suspended mass concentration we correct for wall losses, assuming that organic particles lost to the wall are in equilibrium with the suspended particles and vapor-phase species, and also that the organic to seed mass ratio remains the same for suspended and deposited particles. This is the upper-limit estimate for SOA production. There is approximately a $10 \%$ difference in SOA mass yields for each species studied when assuming particles lost to the walls are in equilibrium with the suspended particles (upper limit) versus assuming that no further condensation occurs once particles have deposited (lower limit). This percentage has been observed in current and past experiments (Chacon-Madrid et al., 2010).

\subsection{Measurement of reactants}

The concentrations of reactants were monitored with a unit mass-resolution proton transfer reaction-mass spectrometer (PTR-MS). The fragments used to track concentrations are those of the MW +1 for $n$-tridecanal, pinonaldehyde, 2- and 7-tridecanone. The PTR-MS sensitivity at these fragment masses was previously calibrated with those species. A key assumption is that interferences from other species were minimal. An exception to this was $n$-tridecanal, discussed in Chacon-Madrid et al. (2010), where a $C_{n-1}$ dicarbonyl is formed due to isomerization.

We used $m / z 43$ and 57 to follow the concentrations and respective consumption of $n$-heptadecanal and $n$-nonadecane. The signal corresponding to their $\mathrm{MW}+1$ was too low, thus a higher-intensity but less selective fragment was used. The specifics of using $m / z, 43$ and 57 with a PTR-MS are described in Jobson et al. (2005) and are also applied in Presto et al. (2010). The difficulty with using either $\mathrm{m} / \mathrm{z} 43$ and 57 as a proxy of reactant concentration is that with time, the signal does not decay as quickly as the precursor is consumed. This is because first- and second-generation products contribute to $m / z, 43$ and 57 as well. In some cases this interference is reduced because the products partition into the aerosol phase and do not produce a PTR-MS signal. We also use methanol as a radical tracer in all experiments. We measured it with a PTR-MS (specifically $\mathrm{m} / \mathrm{z} 33$ ) to determine the concentration of $\mathrm{OH}$ radicals during the experiments. $\mathrm{OH}$ concentrations and kinetic rate constants allow us to predict concentrations of the different precursors and compare with the initial decay of $m / z 43$ and 57. Methanol concentrations in all the experiments conducted were lower than the precursor-molecules themselves. This is done to minimize the effect of methanol on the radical balance. Also, the relatively low rate constant of methanol $+\mathrm{OH}$ radical minimizes its effect on the overall chemistry.

\subsection{Synthesis of organic species}

We synthesized $n$-heptadecanal and pinonaldehyde following McMurry et al. (1987), as they are not commercially available. Products were formed via ozonolysis in solution, as shown in Fig. A in the Supplement. 1-Octadecene (Acros Organics, 90\%) and $\alpha$-pinene (Aldrich, 99\%) were used as reactants for $n$-heptadecanal and pinonaldehyde, respectively. The synthesis started with formation of the secondary ozonide, which was kept stable by maintaining a temperature of $-78^{\circ} \mathrm{C}$ with a dry-ice ethanol slurry. After the ozonide was formed, dimethyl sulfide (DMS) was added to reduce the ozonide to the respective carbonyls. After adding DMS, the products were held at room temperature for about three hours, after which they were extracted with water to remove water-soluble contaminants. Finally, a simple distillation procedure vaporized solvents and other volatile impurities. We used Nuclear Magnetic Resonance $\left(\mathrm{H}^{1} \mathrm{NMR}\right.$, HSQC and Tocsy) to determine products and yields from the synthesis. The spectra are shown in the Supplement in Fig. B through E.

\section{Results}

SOA mass yields for the $10^{5} \mu \mathrm{g} \mathrm{m}^{-3}$ sequence ( $n$-tridecanal, pinonaldehyde, 2- and 7-tridecanone, and $n$-pentadecane) are presented in Figs. 3 and 4. All of these species were exposed to similar $\mathrm{OH}$ and $\mathrm{NO}_{\mathrm{x}}$ concentrations, and none of the reagents showed significant losses to the walls before the $\mathrm{OH}$-radical source was turned on, indicating that wall losses such as those reported by Matsunaga and Ziemann (2010), were not a problem. n-Pentadecane SOA mass yields are shown as a function reproducing data from Presto et al. (2010) and $n$-tridecanal yields are from ChaconMadrid et al. (2010). We shall use the $n$-pentadecane mass yield curve for reference throughout this discussion. $n$-Pentadecane oxidation produces significantly more SOA than either pinonaldehyde or $n$-tridecanal, but within uncertainty, yields for those two aldehydes are identical, as shown in Fig. 3. The 2- and 7-tridecanone SOA mass yields are presented in Fig. 4. Both $n$-ketones have significantly 


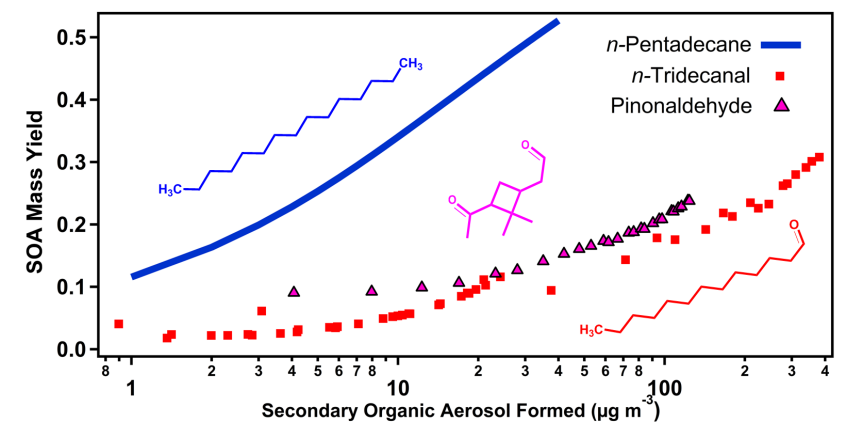

Fig. 3. SOA mass yields of organic species with vapor pressures of $10^{5} \mu \mathrm{g} \mathrm{m}^{-3}$. $n$-Tridecanal, pinonaldehyde and $n$-pentadecane SOA mass yields after the $\mathrm{OH}$ radical reaction at high $\mathrm{NO}_{\mathrm{x}}$ are presented here. $n$-Pentadecane yields are a fit that comes from Presto et al. (2010). The suppression of SOA yields for $n$-tridecanal and pinonaldehyde vs. $n$-pentadecane are related to the tendency of the aldehydic moiety to fragment relatively quickly as detailed in Chacon-Madrid et al. (2010). At this point, it is not clear how the ketone and cyclobutane moieties influence the SOA formation from pinonaldehyde, if at all.

lower SOA mass yields than the reference $n$-alkane, and the 7-tridecanone yields are identical to $n$-tridecanal yields, within error. The 2-tridecanone mass yields are larger than the $n$-tridecanal yields in the 30 to $50 \mu \mathrm{g} \mathrm{m}^{-3}$ range of SOA formed.

SOA mass yields for the $10^{3} \mu \mathrm{g} \mathrm{m}^{-3}$ sequence $(n$ heptadecanal and $n$-nonadecane) are shown in Fig. 5. Because the vapor pressures of the precursors themselves are quite low, we kept the injections and subsequent SOA formation to a relatively low (and atmospherically relevant) range of $<10 \mu \mathrm{g} \mathrm{m}^{-3}$. We do not report yields for cis-pinonic acid in Fig. 5 because we were not confident we could accurately measure its vapor concentrations with the PTR-MS. Nonetheless, cis-pinonic acid oxidation produced a significant amount of SOA, with mass yields appearing to be larger than $n$-heptadecanal but lower than $n$-nonadecane.

The precision of the experiments can be seen in Fig. 3. The SOA mass yields of $n$-tridecanal are composed of two different experiments, one in the region of 0 to $\sim 25 \mu \mathrm{g} \mathrm{m}^{-3}$, and the other in the region of $\sim 25$ to $\sim 400 \mu \mathrm{g} \mathrm{m}^{-3}$. The two experiments form an overlapping yield curve. Pinonaldehyde has a similar mechanism to $n$-tridecanal when reacting with the $\mathrm{OH}$ radical and a similar vapor pressure. Figure 3 shows that yields of pinonaldehyde match those of $n$-tridecanal, again demonstrating the good precision of the measurements. All the experiments performed resulted in SOA mass yields above blank experiments, including the aldehydes.

All the different experiments performed reached equilibrium between the organic aerosol-phase and the gas-phase within the experimental time frame. Particles grew rapidly during the first hour of each experiment due to the high $\mathrm{OH}$ radical concentration, but after the first

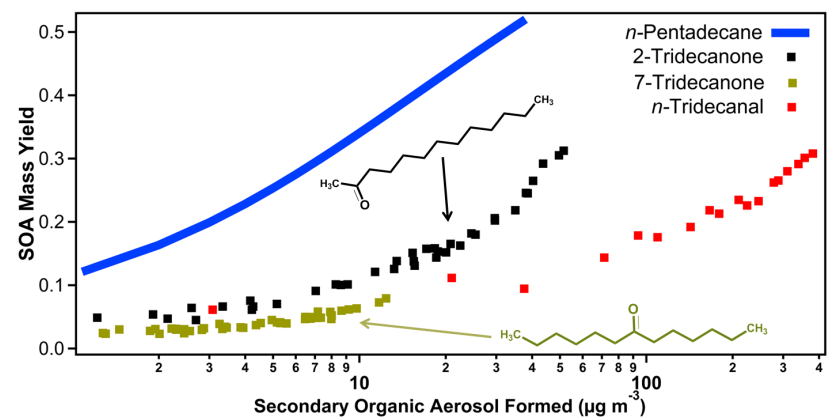

Fig. 4. SOA mass yields of ketones with vapor pressures of $10^{5} \mathrm{\mu g} \mathrm{m}^{-3}$. 2- and 7-tridecanone SOA mass yields are slightly different. The lower efficiency of 7-tridecanone to form SOA might be related to higher fragmentation paths when it reacts with the $\mathrm{OH}$ radical as compared to 2-tridecanone. Additionally, splitting the molecule in the middle might have bigger consequences on SOA production versus splitting it on the side (e.g. 2-tridecanone). However, the differences in SOA yields are not as pronounced as the mechanisms would suggest. Photolysis might play a more important role on the oxidation products of 2-tridecanone.

to second hour of photo-oxidation, the particles stopped growing. There was no evidence for any substantial delay in condensational growth that would be associated with a significant delay in equilibration. This is consistent with other experiments performed in our laboratories (Pierce et al., 2008; Presto et al., 2005). Consequently, we believe that there were no substantial mass-transfer limitations during these experiments that would affect our conclusions regarding the competition between fragmentation, functionalization and accretion effects on SOA formation.

\section{Discussion}

\section{1 $n$-Tridecanal and pinonaldehyde vs. $n$-pentadecane}

The aldehydic moiety appears to dominate $n$-tridecanal and pinonaldehyde chemistry as compared with $n$-pentadecane. This is responsible for the differences in SOA mass yields seen in Fig. 3. Fragmentation overwhelms the firstgeneration chemical mechanism of pinonaldehyde and $n$ tridecanal as discussed in Chacon-Madrid et al. (2010). The fragmentation path is important in the presence of $\mathrm{NO}_{\mathrm{x}}$ (Atkinson and Arey, 2003). The chemical mechanism of a generic aldehyde reacting with $\mathrm{OH}$ radical in the presence of $\mathrm{NO}_{\mathrm{x}}$ is presented in the Supplement, Fig. F.

Fragmentation in the first generation of aldehyde oxidation evidently only occurs when the $\mathrm{OH}$ radical attacks the aldehydic moiety, which tends to be very reactive. For example, according to structure activity relationships (SAR) from Kwok and Atkinson (1995), the aldehydic moiety is attacked $\sim 54 \%$ and $\sim 79 \%$ of the time (relative to other sites in the molecule) for $n$-tridecanal and pinonaldehyde, 


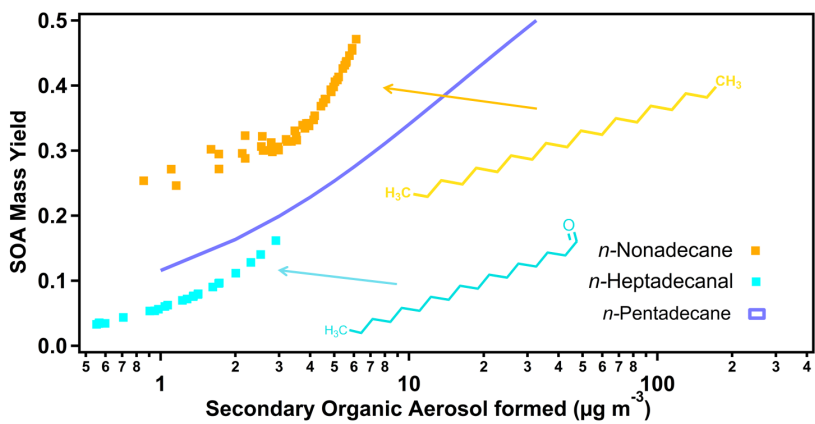

Fig. 5. SOA mass yields of organic species with vapor pressure of $\sim 10^{3} \mu \mathrm{g} \mathrm{m}^{-3}$. $n$-Pentadecane (from the $10^{5} \mu \mathrm{g} \mathrm{m}^{-3}$ sequence) is shown as a reference. The differences in SOA mass yields between $n$-nonadecane and $n$-heptadecanal are not surprising. The aldehydic moiety is very reactive and causes fragmentation at high $\mathrm{NO}_{\mathrm{x}}$, while the $n$-nonadecane does not have relevant first-generation fragmentation paths.

respectively, when attacked by $\mathrm{OH}$. Not every attack on the aldehydic moiety ends in fragmentation, but the molecules that do not fragment after aldehydic attack form peroxyacyl nitrates (PANs) (Singh et al., 1986), which in this case are too volatile to form SOA.

The fragmentation path is thought to be negligible for $n$-pentadecane, at least in the first oxidation steps (Lim and Ziemann, 2005; Atkinson et al., 2008). As shown in Fig. 3, a higher SOA mass yield is the result of functionalizing a molecule without significant fragmentation. Linear $n$-alkanes are especially strong SOA precursors because branched alkanes can fragment more easily, as shown by Lim and Ziemann (2009a, b) and others (Aschmann et al., 2001). While the first-generation oxidation products from pendatecane include carbonyls, they are larger and less volatile than $n$-tridecanal or pinonaldehyde. Since the first oxidation steps for $n$-pentadecane do not include fragmentation, its oxidized products will have significantly lower vapor pressures, making them more likely to partition into the aerosol phase (Pankow, 1994; Donahue et al., 2006).

\section{$4.2 \quad n$-Tridecanal vs. pinonaldehyde}

The two important structural differences between $n$ tridecanal and pinonaldehyde are the four-member cycle and the ketone functionality present in pinonaldehyde but not in $n$-tridecanal. Regardless, the aldehydic moiety is the most reactive in both molecules. Since the aldehydic moiety leads to a significant amount of fragmentation in the presence of $\mathrm{NO}_{\mathrm{x}}$, it is not a surprise to see similar SOA mass yields in these aldehydes that are significantly lower than those of $n$ pentadecane.

The high fragmentation of $n$-tridecanal products was discussed in Chacon-Madrid et al. (2010). Figure 6 presents strong evidence of pinonaldehyde fragmentation to form nor-

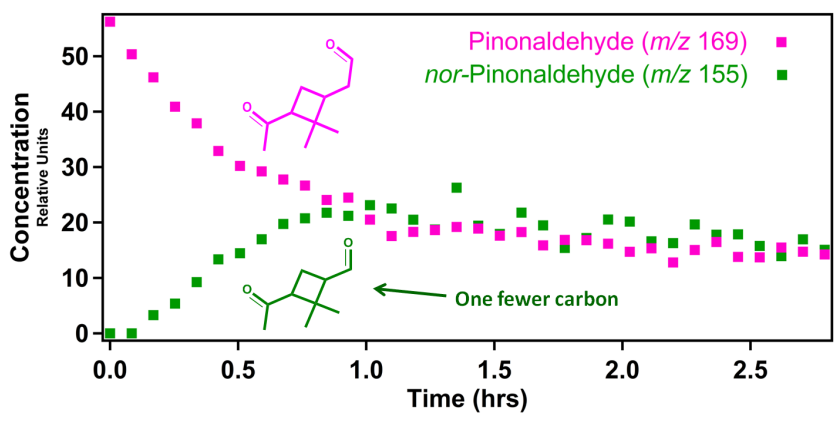

Fig. 6. Pinonaldehyde $+\mathrm{OH}$ radical in the presence of $\mathrm{NO}_{\mathrm{x}}$. Consumption of $\mathrm{m} / \mathrm{z} 169$ (molecular weight of pinonaldehyde +1 in a PTR-MS), and the formation of $m / z, 155$ (molecular weight of norpinonaldehyde +1). nor-Pinonaldehyde molar yield from the $\mathrm{OH}$ radical oxidation of pinonaldehyde in the presence of $\mathrm{NO}_{\mathrm{x}}$ is about $\sim 50 \%$.

pinonaldehyde. In the figure, $t=0$ is the start of photooxidation. The initial $\mathrm{OH}$ radical concentration (determined by consumption of methanol) was $\sim 10^{7}$ molecule $\mathrm{cm}^{-3}$; the $\mathrm{OH}$ concentration dropped by an order of magnitude after the first hour. After about $1.5 \mathrm{~h}$ of photo-oxidation, the norpinonaldehyde signal started to decline because the reaction with $\mathrm{OH}$ exceeded its production due to declining pinonaldehyde levels. These data show that nor-pinonaldehyde (with 9 carbons) forms with a $\sim 50 \%$ molar yield. This is much larger than the $\sim 4 \%$ molar yield of $n$-dodecanal formation from $n$-tridecanal presented in Chacon-Madrid et al. (2010), showing that the $C_{n-1}$ alkoxy radical from pinonaldehyde, with a stiff cyclic backbone, is not capable of isomerizing (Fig. F in the Supplement).

$n$-Tridecanal and pinonaldehyde SOA mass yields are identical within uncertainty (Fig. 3). Two factors may explain this similarity. First, the initial attack by $\mathrm{OH}$ on $n$ tridecanal and pinonaldehyde happens overwhelmingly on the aldehydic moiety, resulting in product-species with one fewer carbon as their major products. Second, even though the aldehydic moiety on pinonaldehyde may be slightly more reactive than $n$-tridecanal (giving more fragmentation), the attack on the rest of the molecule (mainly the four-membercycle) can be very efficient at adding polarity without causing the molecule to split in two different products.

\subsection{2-vs. 7-Tridecanone SOA mass yields}

These two molecules are an ideal model system to explore the importance of the position of the ketone functionality in a molecule and its effect on SOA production. Broadly, if the ketone functionality promotes fragmentation, 7-tridecanone SOA yields could be very small (the molecule would split in half), while 2-tridecanone SOA yields might be intermediate. A hotspot of first-generation reactivity of ketones with the $\mathrm{OH}$ radical is the $\beta$-hydrogens (Atkinson et al., 1982) (Fig. 7). For 7-tridecanone, the $\beta$-hydrogens are thought to 


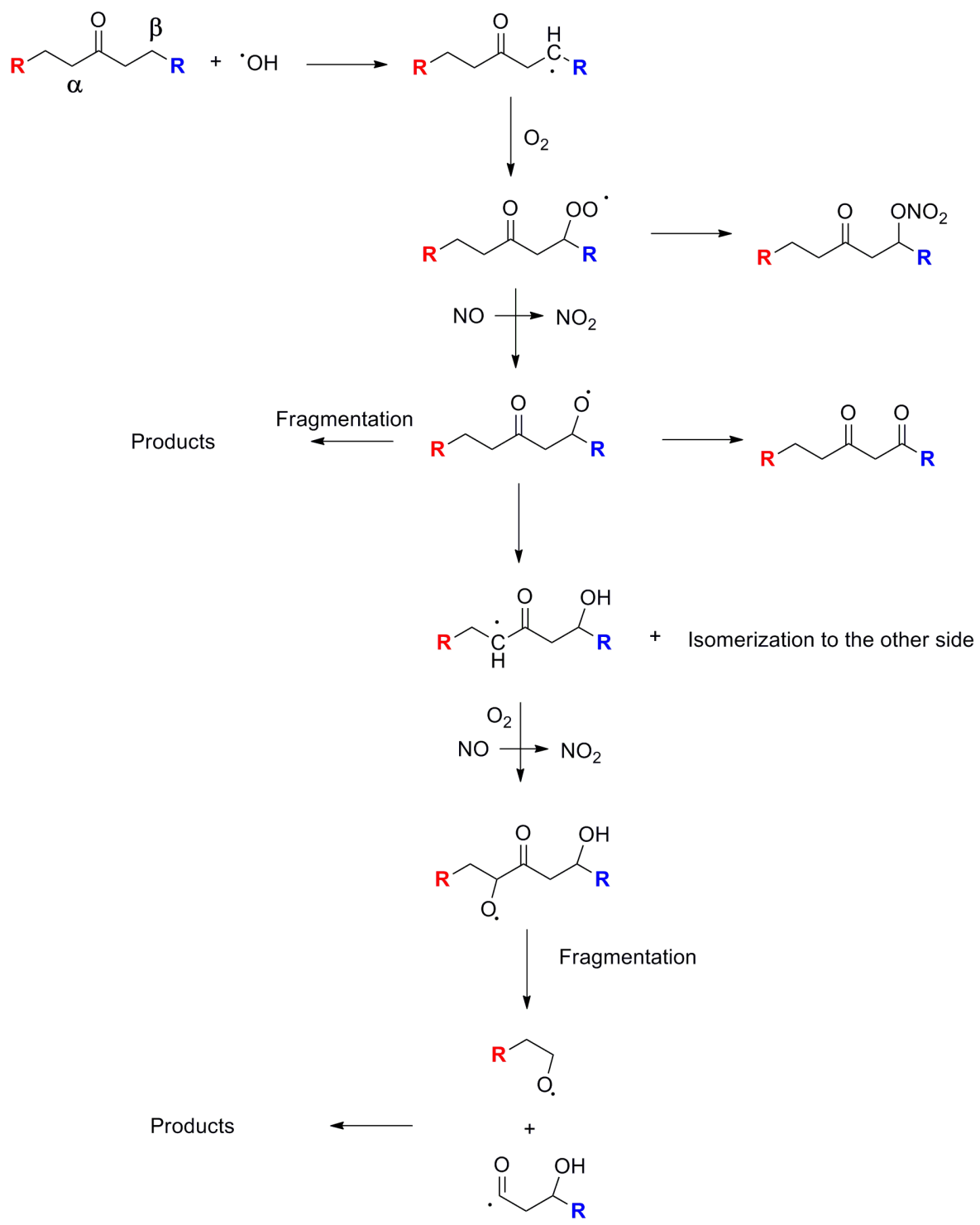

Fig. 7. A partial high- $\mathrm{NO}_{\mathrm{x}} \mathrm{OH}$-radical oxidation mechanism of 7-tridecanone, emphasizing the $\mathrm{OH}$ radical attack of the $\beta$-hydrogens. Figure $\mathrm{G}$ in the Supplement shows evidence of $n$-hexanal formation from the $\mathrm{OH}$ radical oxidation of 7 -tridecanone at high $\mathrm{NO}_{\mathrm{x}}$.

account for $\sim 47 \%$ of the first-generation reaction with the $\mathrm{OH}$ radical (following Kwok and Atkinson, 1995).

For 2-tridecanone, attack on $\beta$-hydrogens is only $\sim 27 \%$ because there is only one $\beta$-carbon. A partial mechanism for 7tridecanone is presented in Fig. 7, showing the attack on the $\beta$-hydrogens that can lead to fragmentation. This fragmentation path results in the formation of $n$-hexanal, which we observed by PTR-MS (Fig. G, Supplement). This particular fragmentation path might not be important for 2-tridecanone because of the low reactivity of the terminal $\mathrm{CH}_{3}$ - with the $\beta$-alkoxy radical at the isomerization stage. Attack on the $\alpha$ hydrogens could also lead to fragmentation: this path could lead to an $\alpha$-alkoxy radical that would preferably fragment (Kroll and Seinfeld, 2008). However, the reactivity of the $\alpha$ - hydrogens by $\mathrm{OH}$ radical is thought to be slightly reduced because of the presence of the carbonyl (Atkinson et al., 1982), making this a minor pathway.

The consequence of having a ketone functional group in the center versus the side can be seen in Fig. 4. Fragmenting a molecule in the center divides it into two higher vaporpressure product molecules, which suppresses SOA formation. It is clear in Fig. 4 that 2-tridecanone is more efficient at forming SOA, as expected. However, it is somewhat surprising that the 2-tridecanone SOA yields are as low as they are. This could be due to photolysis of the oxidation products, given that Presto et al. (2005) has shown that UV lights can have an important suppression effect on SOA formation, but this requires further investigation. 


\section{$4.4 n$-Nonadecane, $n$-heptadecanal and cis-pinonic acid}

The less volatile sequence follows a similar pattern as the more volatile sequence, as shown in Fig. $5 . n$ Nonadecane has significantly higher SOA mass yields than $n$-heptadecanal. The aldehyde again presents lower SOA mass yields due to higher fragmentation. It is not obvious that this should be so. As an $n$-aldehyde becomes as large as $n$-heptadecane, its reactivity and SOA yields might resemble that of an $n$-alkane of comparable volatility rather than smaller aldehydes, simply because the long carbon backbone and not the aldehydic moiety would become the principal site of OH attack (Chacon-Madrid et al., 2010). Furthermore, a molecule as large as $n$-heptadecane might have a slightly different oxidation mechanism than smaller $n$ aldehydes $\left(<C_{11}\right)$, even if the aldehydic moiety plays a role. For example, alkoxy radicals formed on the carbon backbone of $n$-heptadecanal are more likely to isomerize towards the aldehydic functionality, promoting fragmentation. This path was proposed by Jenkin et al. (2000), where an acyl-oxy radical formed from the ozonolysis of $\alpha$-pinene attacks an internal aldehydic moiety. However, we do not have direct evidence to support this proposed pathway. Another reason for the relatively low SOA yields from $n$-heptadecanal could be higher photolysis rates for the reaction products, compared to $n$-nonadecane.

As mentioned before, we did not present SOA mass yields for cis-pinonic acid in Fig. 5 because of difficulty measuring the cis-pinonic acid concentration. Nonetheless, based on injected quantities, yields appeared to be higher than the similar vapor pressure aldehyde but lower than the respective $n$-alkane. The probable strength of the SOA yields from cis-pinonic acid is related to its cyclic structure. The first-generation $\mathrm{OH}$ radical attack favors two of the tertiarycarbons and the secondary-carbon placed in the cycle. Even if an intermediate alkoxy radical is able to create a carboncarbon scission, only one product is formed instead of two of higher-volatility.

\section{Environmental significance}

Understanding how SOA formation capability evolves through the full oxidation sequence of organics in the atmosphere is critical in order to improve predictions of ambient SOA formation and evolution. Most chemical transport models (CTMs) under-predict the concentrations of organic aerosol (Appel et al., 2008; Zhang et al., 2009). This may be due to the lack of multi-generation oxidation mechanisms in CTMs. In this paper, we have systematically explored the oxidation of different molecules that are proxies for first-generation oxidation products. From $n$-pentadecane, $n$-tridecanal, 2-, 7-tridecanone and pinonaldehyde to $n$ nonadecane, $n$-heptadecanal and cis-pinonic acid, we noticed a higher susceptibility for more oxidized molecules to frag- ment more easily than less oxidized species of similar vapor pressures, based on SOA mass yields. However, neither oxidation state nor $\mathrm{O}: \mathrm{C}$ is enough to predict the ability of a species to produce SOA. All oxidized organics produce less SOA than $n$-alkanes of similar vapor pressures, but there are specific moieties - such as aldehydes under high- $\mathrm{NO}_{\mathrm{x}}$ conditions - that can fragment efficiently in the first generation of the $\mathrm{OH}$ radical attack. The presence of these moieties, rather than $\mathrm{O}: \mathrm{C}$ in general, appears to be important to SOA formation.

Our major conclusion is that even though carbon backbones become more susceptible to fragmentation as they age, that aging can still add substantially to organic aerosol formation. While more oxidized molecules are more likely to fragment, they will also contribute significantly to organic aerosol formation. For example, pinonaldehyde, a major product of $\alpha$-pinene, has SOA yields very similar to those of $\alpha$-pinene itself (Presto and Donahue, 2006). cis-Pinonic acid also has substantial yields. It is critical to understand the contribution of SOA from aging mechanisms and implement them in CTMs in order to better predict organic aerosol levels and properties. This work represents the beginning of that process - it does not include highly oxidized species and makes no conclusions with regards to the heterogeneous oxidation of such species. Ultimately, we hope to be able to select key model species throughout the 2-D space shown in Fig. 2 in order to constrain the full kinetics and mechanisms of organic-aerosol evolution caused by gasphase photo-oxidation.

\section{Supplementary material related to this article is available online at: http://www.atmos-chem-phys.net/11/10553/2011/ acp-11-10553-2011-supplement.zip.}

Acknowledgements. This research was supported by the Electric Power Research Institute grant EPP25369C12290 and the EPA STAR program through the National Center for Environmental Research (NCER). This paper has not been subject to EPA's required peer and policy review, and therefore does not necessarily reflect the views of the Agency. No official endorsement should be inferred.

Edited by: H. Saathoff

\section{References}

Aiken, A. C., DeCarlo, P. F., Kroll, J. H., Worsnop, D. R., Huffman, J. A., Docherty, K. S., Ulbrich, I. M., Mohr, C., Kimmel, J. R., Sueper, D., Sun, Y., Zhang, Q., Trimborn, A., Northway, M., Ziemann, P. J., Canagaratna, M. R., Onasch, T. B., Alfarra, M. R., Prevot, A. S. H., Dommen, J., Duplissy, J., Metzger, A., Baltensperger, U., and Jimenez, J. L.: O/C and OM/OC Ratios of Primary, Secondary, and Ambient Organic Aerosols with High- 
Resolution Time-of-Flight Aerosol Mass Spectrometry, Environ. Sci. Technol., 42, 4478-4485, 2008.

Appel, K. W., Bhave, P. V., Gilliland, A. B., Sarwar, G., and Roselle, S. J.: Evaluation of the community multiscale air quality (CMAQ) model version 4.5: Sensitivities impacting model performance; Part II particulate matter, Atmos. Environ., 42, 60576066, 2008.

Arey, J., Aschmann, S. M., Kwok, E. S. C., and Atkinson, R.: Alkyl Nitrate, Hydroxyalkyl Nitrate, and Hydroxycarbonyl Formation from the $\mathrm{NO}_{\mathrm{x}}$-Air Photooxidations of $\mathrm{C}_{5}-\mathrm{C}_{8} n$-Alkanes, J. Phys. Chem. A, 105, 1020-1027, 2001.

Aschmann, S. M., Arey, J., and Atkinson, R.: Atmospheric Chemistry of Three $\mathrm{C}_{10}$ Alkanes, J. Phys. Chem., 105, 7598-7606, 2001.

Atkinson, R.: Atmospheric chemistry of VOCs and $\mathrm{NO}_{\mathrm{x}}$, Atmos. Environ., 34, 2063-2101, 2000.

Atkinson, R.: Rate constants for the atmospheric reactions of alkoxy radicals: An updated estimation method, Atmos. Environ., 41, 8468-8485, 2007.

Atkinson, R. and Arey, J.: Atmospheric Degradation of Volatile Organic Compounds, Chem. Rev., 103, 4605-4638, 2003.

Atkinson, R., Aschmann, S. M., Carter, W. P. L., and Jr., J. N. P.: Rate Constants for the Gas-Phase Reaction of $\mathrm{OH}$ Radicals with a Series of Ketones at $299 \pm 2$ K, Int. J. Chem. Kinet., 14, 839847, 1982.

Atkinson, R., Aschmann, S. M., and Winer, A. M.: Alkyl nitrate formation from the reaction of a series of branched $\mathrm{RO} 2$ radicals with $\mathrm{NO}$ as a function of temperature and pressure, J. Atmos. Chem., 5, 91-102, 1987.

Atkinson, R., Arey, J., and Aschmann, S. M.: Atmospheric chemistry of alkanes: Review and recent develpments, Atmos. Environ., 42, 5859-5871, 2008.

Balkanski, Y. J., Jacob, D. J., Gardner, G. M., Graustein, W. C., and Turekian, K. K.: Transport and Residence Times of Tropospheric Aerosols Inferred from a Global Three-Dimensional Simulation of ${ }^{210} \mathrm{~Pb}$, J. Geophys. Res., 98, 20573-20586, 1993.

Chacon-Madrid, H. J., Presto, A. A., and Donahue, N. M.: Functionalization vs. Fragmentation: $n$-Aldehyde Oxidation Mechanisms and Secondary Organic Aerosol Formation, Phys. Chem. Chem. Phys., 12, 13975-13982, 2010.

Donahue, N. M., Robinson, A. L., Stanier, C. O., and Pandis, S. N.: Coupled Partitioning, Dilution, and Chemical Aging of Semivolatile Organics, Environ. Sci. Technol., 40, 2635-2643, 2006.

Donahue, N. M., Epstein, S. A., Pandis, S. N., and Robinson, A. L.: A two-dimensional volatility basis set: 1. organic-aerosol mixing thermodynamics, Atmos. Chem. Phys., 11, 3303-3318, doi:10.5194/acp-11-3303-2011, 2011a.

Donahue, N. M., Kroll, J. H., Pandis, S. N., and Robinson, A. L.: A two-dimensional volatility basis set - Part 2: Diagnostics of organic-aerosol evolution, Atmos. Chem. Phys. Discuss., 11, 24883-24931, doi:10.5194/acpd-11-24883-2011, 2011b.

George, I., Vlasenko, A., Slowik, J., Abbatt, J., O’Dowd, C. D., and Wagner, P. E.: Heterogeneous Oxidation of Saturated Organic Particles by $\mathrm{OH}$ in: Nucleation and Atmospheric Aerosols, Springer Netherlands, 736-740, 2007.

Glasius, M., Calogirou, A., Jensen, N. R., Hjorth, J., and Nielsen, C. J.: Kinetic Study of Gas-Phase Reactions of Pinonaldehyde and Structurally Related Compounds, Int. J. Chem. Kinet., 29,
527-533, 1997.

Goldstein, A. H. and Galbally, I. E.: Known and Unexplored Organic Constituents in the Earth's Atmosphere, Environ. Sci. Technol., 41, 1514-1521, 2007.

Hallquist, M., Wenger, J. C., Baltensperger, U., Rudich, Y., Simpson, D., Claeys, M., Dommen, J., Donahue, N. M., George, C., Goldstein, A. H., Hamilton, J. F., Herrmann, H., Hoffmann, T., Iinuma, Y., Jang, M., Jenkin, M. E., Jimenez, J. L., Kiendler-Scharr, A., Maenhaut, W., McFiggans, G., Mentel, Th. F., Monod, A., Prévôt, A. S. H., Seinfeld, J. H., Surratt, J. D., Szmigielski, R., and Wildt, J.: The formation, properties and impact of secondary organic aerosol: current and emerging issues, Atmos. Chem. Phys., 9, 5155-5236, doi:10.5194/acp-95155-2009, 2009.

Hatakeyama, S., Izumi, K., Fukuyama, T., and Akimoto, H. J.: Reactions of Ozone with a-Pinene and b-Pinene in Air: Yields of Gaseous and Particulate Products, J. Geophys. Res., 94, 1301313024, 1989.

Hatakeyama, S., Izumi, K., Fukuyama, T., Akimoto, H., and Washida, N.: Reactions of $\mathrm{OH}$ with a-Pinene and b-Pinene in Air: Estimate of Global Co Production from the Atmospheric Oxidation of Terpenes, J. Geophys. Res., 96, 947-958, 1991.

Hildebrandt, L., Donahue, N. M., and Pandis, S. N.: High formation of secondary organic aerosol from the photo-oxidation of toluene, Atmos. Chem. Phys., 9, 2973-2986, doi:10.5194/acp-92973-2009, 2009.

Jenkin, M. E., Shallcross, D. E., and Harvey, J. N.: Development and application of a possible mechanism for the generation of cis-pinic acid from the ozonolysis of $\alpha$ - and $\beta$-pinene, Atmos. Environ., 34, 2837-2850, 2000.

Jimenez, J. L., Canagaratna, M. R., Donahue, N. M., Prevot, A. S. H., Zhang, Q., Kroll, J. H., DeCarlo, P. F., Allan, J. D., Coe, H., Ng, N. L., Aiken, A. C., Docherty, K. S., Ulbrich, I. M., Grieshop, A. P., Robinson, A. L., Duplissy, J., Smith, J. D., Wilson, K. R., Lanz, V. A., Hueglin, C., Sun, Y. L., Tian, J., Laaksonen, A., Raatikainen, T., Rautiainen, J., Vaattovaara, P., Ehn, M., Kulmala, M., Tomlinson, J. M., Collins, D. R., Cubison, M. J., E, Dunlea, J., Huffman, J. A., Onasch, T. B., Alfarra, M. R., Williams, P. I., Bower, K., Kondo, Y., Schneider, J., Drewnick, F., Borrmann, S., Weimer, S., Demerjian, K., Salcedo, D., Cottrell, L., Griffin, R., Takami, A., Miyoshi, T., Hatakeyama, S., Shimono, A., Sun, J. Y., Zhang, Y. M., Dzepina, K., Kimmel, J. R., Sueper, D., Jayne, J. T., Herndon, S. C., Trimborn, A. M., Williams, L. R., Wood, E. C., Middlebrook, A. M., Kolb, C. E., Baltensperger, U., and Worsnop, D. R.: Evolution of Organic Aerosols in the Atmosphere, Science, 326, 1525-1529, 2009.

Jobson, B. T., Alexander, M. L., Maupin, G. D., and Muntean, G. G.: On-line analysis of organic compounds in diesel exhaust using a proton transfer reaction mass spectrometer (PTR-MS), Int. J. Mass Spectrom., 245, 78-89, 2005.

Kalberer, M., Paulsen, D., Sax, M., Steinbacher, M., Dommen, J., Prevot, A. S. H., Fisseha, R., Weingartner, E., Frankevich, V., Zenobi, R., and Baltensperger, U.: Identification of Polymers as Major Components of Atmospheric Organic Aerosols, Science, 303, 1659-1166, 2004.

Kalberer, M., Sax, M., and Samburova, V.: Molecular Size Evolution of Oligomers in Organic Aerosols Collected in Urban Atmospheres and Generated in a Smog Chamber, Environ. Sci. Technol., 40, 5917-5922, 2006. 
Kanakidou, M., Seinfeld, J. H., Pandis, S. N., Barnes, I., Dentener, F. J., Facchini, M. C., Van Dingenen, R., Ervens, B., Nenes, A., Nielsen, C. J., Swietlicki, E., Putaud, J. P., Balkanski, Y., Fuzzi, S., Horth, J., Moortgat, G. K., Winterhalter, R., Myhre, C. E. L., Tsigaridis, K., Vignati, E., Stephanou, E. G., and Wilson, J.: Organic aerosol and global climate modelling: a review, Atmos. Chem. Phys., 5, 1053-1123, doi:10.5194/acp-5-1053-2005, 2005.

Kroll, J. H. and Seinfeld, J. H.: Chemistry of secondary organic aerosol: Formation and evolution of low-volatility organics in the atmosphere, Atmos. Environ., 42, 3593-3624, 2008.

Kroll, J. H., Smith, J. D., Che, D. L., Kessler, S. H., Worsnop, D. R., and Wilson, K. R.: Measurement of fragmentation and functionalization pathways in the heterogeneous oxidation of oxidized organic aerosol, Phys. Chem. Chem. Phys., 11, 8005-8014, 2009.

Kroll, J. H., Donahue, N. M., Jimenez, J. L., Kessler, S. H., Canagaratna, M. R., Wilson, K. R., Altieri, K. E., Mazzoleni, L. R., Wozniak, A. S., Bluhm, H., Mysak, E. R., Smith, J. D., Kolb, C. E., and Worsnop, D. R.: Carbon oxidation state as a metric for describing the chemistry of atmospheric organic aerosol, Nat. Chem., 3, 133-139, 2011.

Kwok, E. S. C. and Atkinson, R.: Estimation of Hydroxyl Radical Reaction Rate Constants for Gas-Phase Organic Compounds Using a Structure-Reactivity Relationship: An Update, Atmos. Environ., 29, 1685-1695, 1995.

Kwok, E. S. C., Arey, J., and Atkinson, R.: Alkoxy Radical Isomerization in the $\mathrm{OH}$ Radical-Initiated Reactions of $\mathrm{C}_{4}-\mathrm{C}_{8} n$ Alkanes, J. Phys. Chem., 100, 214-219, 1996.

Lim, Y. B. and Ziemann, P. J.: Products and Mechanism of Secondary Organic Aerosol Fromation from Reactions of n-Alkanes with $\mathrm{OH}$ Radicals in the Presence of $\mathrm{NO}_{\mathrm{x}}$, Environ. Sci. Technol., 39, 9229-9236, 2005.

Lim, Y. B. and Ziemann, P. J.: Effects of Molecular Structure on Aerosol Yields from $\mathrm{OH}$ Radical-Initiated Reactions of Linear, Branched, and Cyclic Alkanes in the Presence of $\mathrm{NO}_{\mathrm{x}}$, Environ. Sci. Technol., 43, 2328-2334, 2009a.

Lim, Y. B. and Ziemann, P. J.: Chemistry of Secondary Organic Aerosol Formation from OH Radical-Initiated Reactions of Linear, Branched, and Cyclic Alkanes in the Presence of $\mathrm{NO}_{\mathrm{x}}$, Aerosol Sci. Tech., 43, 604-619, 2009b.

Matsunaga, A. and Ziemann, P. J.: Gas-Wall Partitioning of Organic Compounds in a Teflon Film Chamber and Potential Effects on Reaction Product and Aerosol Yield Measurements, Aerosol Sci. Tech., 44, 881-892, 2010.

McMurry, J. E. and Bosch, G. K.: Synthesis of macrocyclic terpenoid hydrocarbons by intramolecular carbonyl coupling: bicyclogermacrene, lepidozene, and casbene, J. Org. Chem., 52, 4885-4893, 1987.

Ng, N. L., Canagaratna, M. R., Zhang, Q., Jimenez, J. L., Tian, J., Ulbrich, I. M., Kroll, J. H., Docherty, K. S., Chhabra, P. S., Bahreini, R., Murphy, S. M., Seinfeld, J. H., Hildebrandt, L., Donahue, N. M., DeCarlo, P. F., Lanz, V. A., Prévôt, A. S. H., Dinar, E., Rudich, Y., and Worsnop, D. R.: Organic aerosol components observed in Northern Hemispheric datasets from Aerosol Mass Spectrometry, Atmos. Chem. Phys., 10, 46254641, doi:10.5194/acp-10-4625-2010, 2010.

Odum, J. R., Hoffmann, T., Bowman, F., Collins, D., Flagan, R. C., and Seinfeld, J. H.: Gas/Particle Partitioning and Secondary Organic Aerosol Yields, Environ. Sci. Technol., 30, 2580-2585,
1996.

Pankow, J. F.: An Absorption Model of Gas/Particle Partitioning of Organic Compounds in the Atmosphere, Atmos. Environ., 28, 185-188, 1994.

Pankow, J. F. and Asher, W. E.: SIMPOL.1: a simple group contribution method for predicting vapor pressures and enthalpies of vaporization of multifunctional organic compounds, Atmos. Chem. Phys., 8, 2773-2796, doi:10.5194/acp-8-27732008, 2008.

Pierce, J. R., Engelhart, G. J., Hildebrandt, L., Weitkamp, E. A., Pathak, R. K., Donahue, N. M., Robinson, A. L., Adams, P. J., and Pandis, S. N.: Constraining Particle Evolution from Wall Losses, Coagulation, and Condensation-Evaporation in SmogChamber Experiments: Optimal Estimation Based on Size Distribution Measurements, Aerosol Sci. Technol., 42, 1001-1015, 2008.

Presto, A. and Donahue, N. M.: Investigation of alpha-pinene + ozone secondary organic aerosol formation at low total aerosol mass, Environ. Sci. Technol., 40, 3546-3543, 2006.

Presto, A. A., Huff Hartz, K. E., and Donahue, N. M.: Secondary Organic Aerosol Production from Terpene Ozonolysis. 1. Effect of UV Radiation, Environ. Sci. Technol., 39, 7036-7045, 2005.

Presto, A. A., Miracolo, M. A., Donahue, N. M., and Robinson, A. L.: Secondary Organic Aerosol Formation from High-NOx Photo-Oxidation of Low Volatility Precursors: $n$-Alkanes, Environ. Sci. Technol., 44, 2029-2034, doi:10.1021/es903712r, 2010.

Rudich, Y., Donahue, N. M., and Mentel, T. F.: Aging of Organic Aerosol: Bridging the Gap Between Laboratory and Field Studies, Annu. Rev. Phys. Chem., 58, 321-352, 2007.

Schauer, J. J., Kleeman, M. J., Cass, G. R., and Simoneit, B. R. T.: Measurement of Emissions from Air Pollution Sources, Part 2, $\mathrm{C}_{1}$ through $\mathrm{C}_{30}$ Organic Compounds from Medium Duty Diesel Trucks, Environ. Sci. Technol., 33, 1578-1587, 1999a.

Schauer, J. J., Kleeman, M. J., Cass, G. R., and Simoneit, B. R. T.: Measurement of Emissions from Air Pollution Sources, Part. 1, $\mathrm{C}_{1}$ through $\mathrm{C}_{29}$ Organic Compounds from Meat Charbroiling, Environ. Sci. Technol., 33, 1566-1577, 1999b.

Schradera, W., Geigerb, J., and Godejohann, M.: Studies of complex reactions using modern hyphenated methods: $\alpha$-Pinene ozonolysis as a model reaction, J. Chromatogr. A, 1075, 185196, 2005.

Singh, H. B., Salas, L. J., and Viezee, W.: Global distribution of peroxyacetyl nitrate, Nature, 321, 588-591, 1986.

Smith, J. D., Kroll, J. H., Cappa, C. D., Che, D. L., Liu, C. L., Ahmed, M., Leone, S. R., Worsnop, D. R., and Wilson, K. R.: The heterogeneous reaction of hydroxyl radicals with submicron squalane particles: a model system for understanding the oxidative aging of ambient aerosols, Atmos. Chem. Phys., 9, 3209-3222, doi:10.5194/acp-9-3209-2009, 2009.

Zhang, Y., Vijayaraghavan, K., Wen, X.-Y., Snell, H. E., and Jacobson, M. Z.: Probing into regional ozone and particulate matter pollution in the United States: Part 1, A 1 year CMAQ simulation and evaluation using surface and satellite data, J. Geophys. Res., 114, 1-31, 2009. 